http://dx.doi.org/10.5007/1981-1322.2014v9nespp38

\title{
A pesquisa em Modelagem Matemática na Educação Matemática: sobre as atividades de formação continuada em teses e dissertações
}

\author{
Research in mathematical modeling in mathematics education: about continued \\ formation activities in theses and dissertations
}

\author{
Carla Melli Tambarussi ${ }^{1}$ \\ carlatambarussi@hotmail.com
}

Tiago Emanuel Klüber ${ }^{2}$

tiagokluber@gmail.com

\begin{abstract}
Resumo
Um dos desdobramentos da nossa investigação de mestrado, e que também está inserido no contexto de um projeto de pesquisa ${ }^{3}$, é a formação continuada de professores. Nesse sentido, orientados pela interrogação: $O$ que se mostra das atividades de formação continuada de professores nas pesquisas de dissertações e teses de Modelagem na Educação Matemática?, na presente investigação voltamos nosso olhar para as dissertações e teses que em seu âmbito trataram das atividades de formação continuada. Em um primeiro momento, efetuamos o levamento desses trabalhos, que resultou em 8 dissertações e 1 tese. No segundo momento, eles foram analisados e categorizados segundo as suas próprias informações. Desenvolvemos a pesquisa sob a perspectiva fenomenológica e utilizamos o software Atlas. T.i. no processo de análise e categorização dos dados. Realizamos interpretações decorrentes dos dados analisados que nos permitem afirmar que as atividades de formação continuada em Modelagem têm como principal característica o "fazer Modelagem", e em muitos casos não contemplam aspectos mais abrangentes da formação de professores e da própria Modelagem.
\end{abstract}

Palavras-chave: Fenomenologia. Análise hermenêutica. Formação de professores.

\begin{abstract}
One of the outcomes of our master, and that also placed in the context of a research project, is the teachers continued formation. In this sense, conducted by the question: What is shows the teachers continued formation activities in research of dissertations and theses Modeling in Mathematics Education?, in this study we aproach

\footnotetext{
${ }^{1}$ Mestranda do Programa de Pós-graduação em Educação, PPGE. Universidade Estadual do Oeste do Paraná, Unioeste, Cascavel.

${ }^{2}$ Doutor em Educação Científica e Tecnológica. Professor Adjunto na Universidade Estadual do Oeste do Paraná, Colegiado de Matemática. Docente do Programa de Pós-Graduação em Educação, PPGE, Unioeste/Unioeste, Cascavel. Docente do Programa de Pós-Graduação em Ensino, PPGEn, Unioeste, Foz do Iguaçu.

3 Projeto de Pesquisa Modelagem Matemática na Educação Matemática: Metapesquisa e Formação de Professores, aprovado no edital universal da Coordenação de Aperfeiçoamento de Pessoal de Nível Superior CAPES, sobre o processo de número: 406721/2013-0.
} 
to the dissertations and theses that in this scope addressed the continued formation activities. At first, we perfom a search of these researches, which resulted in 8 dissertations and 1 thesis. In the second moment, they were analyzed and categorized according to their own information. We develop the research from the phenomenological perspective and use the software Atlas. T.i. in the analysis and categorization of the data process. During the research, we perform interpretations of the data analyzed that allow us to state that the activities of continued formation in Modeling has as main feature the " do modeling ", and in many cases do not address broader aspects of teacher education and the own Modeling.

Keywords: Phenomenology. Hermeneutical analysis. Teachers education.

\section{Objeto $^{4}$ e contexto da pesquisa}

Ao discutir e retomar de modo constante o mesmo objeto de pesquisa, diversos caminhos e possibilidades de reflexão se abrem. É nesse sentido que distintos aspectos referentes à formação continuada de professores têm se mostrado pertinentes e carentes de aprofundamentos.

No entanto, o leitor pode se perguntar: por que a formação continuada? Isso se deve, ao movimento de nos voltarmos de modo constante à nossa interrogação de pesquisa que será desenvolvida no âmbito de uma investigação de mestrado. E ao indagarmos para "que lugar a interrogação nos conduz", deparamo-nos com o PDE - Programa de Desenvolvimento Educacional do Estado do Paraná. Este, por sua vez, desde o ano de 2010, é considerado uma política de estado para a formação continuada da Rede Pública Estadual de Ensino do Paraná (PARANÁ, 2013).

Nesse contexto, caminhos de pesquisa se abriram e fomos remetidos, também, à busca por compreensão de distintos modos de o fenômeno se manisfestar. E um deles concerne, especificamente, à formação continuada de professores no âmbito da Modelagem na Educação Matemática. Por um lado, uma vez que nos debruçamos sobre dissertações e teses no âmbito da formação de professores, identificamos que há um considerável número de investigações sobre a temática, como já apontamos em outra oportunidade (TAMBARUSSI; KLÜBER, 2014). De outro, em termos de metapesquisa, ainda não foram efetuados estudos que retomem aspectos mais abrangentes das atividades de formação continuada trabalhadas nestas investigações. Assim, entendemos que essa temática posta em destaque por nós, vai ao

\footnotetext{
${ }^{4}$ Bicudo (1999, p. 18) esclarece que afirmar que a consciência não tem nada fora de si, quer dizer que nesse movimento de voltar-se para, de estender-se a, ela já enlaça o objeto das suas vivências e, com isso, esse objeto é sempre intencional.

O termo objeto intencional é usado de maneira equivalente ao termo fenômeno para manter a diferenciação do objeto no sentido realista, e, portanto, metafísico da realidade (KLÜBER, 2012, p. 53).
} 
encontro, transitivamente, das demandas de pesquisa indicadas nos relatórios do Grupo de Pesquisa em Modelagem Matemática, GT10, da Sociedade Brasileira de Educação Matemática. Eles indicaram, por exemplo, que há carência de estudos sobre “[...] as fronteiras entre pesquisa sobre modelagem e a prática de modelagem dos professores" (BARBOSA; ARAÚJO; CALDEIRA, 2009, p. 6).

Sob essa orientação compreendemos que o objeto de nossa pesquisa, ora apresentado, se revela como uma possível contribuição para o campo, uma vez que enlaça, de modo articulado, a metapesquisa e a formação de professores em Modelagem. Em outras palavras, nos inserimos na fronteira entre a pesquisa e a prática, conforme indicaram os relatores.

O nosso estudo, portanto, dialoga com a dinâmica da pesquisa solicitada e fomentada pela comunidade de Modelagem Matemática, tomando um objeto de pesquisa diferente de outros metaestudos que foram realizados recentemente, tais como: Niss (2001), Almeida (2006), Barbosa (2007), Araújo (2009) e mais recentemente Bicudo e Klüber (2011), Klüber e Burak (2012).

Nesse sentido, e de modo mais específico, num movimento fenomenológico de investigação, destacamos um dos aspectos referentes à formação continuada em Modelagem: as atividades oferecidas aos professores. Esse objeto, no solo em que apresentamos, foi investigado sob a seguinte interrogação de pesquisa: O que se mostra das atividades de formação continuada de professores nas pesquisas de dissertações e teses de Modelagem na Educação Matemática?

Essa interrogação se originou e conduziu a investigação desde uma abordagem de pesquisa qualitativa segundo a visão Fenomenológica (BICUDO, 2011). E, ao estabelecermos essa interrogação, direcionamos o nosso olhar, transitivamente, para as pesquisas já desenvolvidas na temática da formação continuada de professores em Modelagem Matemática, de modo particular, para atividades de formação descritas nas pesquisas de dissertações e teses. A característica da nossa interrogação, a partir da leitura de Bicudo e Paulo, (2011, p. 255) "conduz ao movimento da meta-pesquisa, ou seja, pesquisa sobre a pesquisa, ou ainda, sobre a própria produção".

$\mathrm{Na}$ busca por esclarecer o movimento de investigação sob a interrogação estabelecida, na próxima seção do trabalho, explicitamos os aspectos metodológicos da nossa pesquisa. Desse modo, pretendemos situar o leitor no que diz respeito à pesquisa qualitava sob um enfoque 
fenomenológico. Apresentamos, também, os procedimentos adotados, com o objetivo de mostrar como se deu o processo de recolha e, posteriormente, de análise dos dados.

Ainda, no sentido de expor a estrutura do trabalho, em uma das seções efetuamos as interpretações das categorias que emergiram do estudo, na qual trazemos reflexões sobre o que tem sido pesquisado em relação às atividades de formação continuada de professores e à Modelagem Matemática no âmbito da Educação Matemática.

\section{Aspectos Metodológicos}

Ao assumirmos a interrogação, $O$ que se mostra das atividades de formação continuada de professores nas pesquisas de dissertações e teses de Modelagem na Educação Matemática?, outras possibilidades investigativas se abriram e fomos conduzidos pelo próprio fenômeno num caminho que lhe pertence (PALMER, 1996).

Nesse sentido, para o levantamento dos trabalhos que eram pertinentes ao nosso propósito, retomamos o nosso artigo em que realizamos um mapeamento, no Banco de Teses da Capes, do que tem sido pesquisado em Modelagem Matemática no âmbito da Educação Matemática de 1989 a 2011 (TAMBARUSSI; KLÜBER, 2014).

A partir desse trabalho, identificamos as investigações relacionadas à formação de professores em Modelagem e após a leitura dos seus resumos distinguimos aquelas que são específicas da formação continuada de professores. Dos 15 trabalhos cuja temática é a formação de professor, 9 dizem do recorte estabelecido para essa investigação, sendo que 2 são dissertações de mestrado profissional, 6 de mestrado acadêmico e apenas 1 constitui-se em tese de doutorado.

No entanto, para que pudéssemos dar continuidade a este trabalho e buscar responder a interrogação de pesquisa se fazia necessário muito mais do que ler os resumos das dissertações e da tese, era necessário obter essas 9 investigações na íntegra. Para isso, efetuamos um levantamento nos sites das universidades nas quais os trabalhos foram defendidos e como, em alguns casos, não obtivemos êxito, entramos em contato com 3 pesquisadores que forneceram seus trabalhos. A partir desses procedimentos conseguimos reunir 8 trabalhos. 
Nesse sentido, com vistas a apresentar ao leitor os trabalhos utilizados em nossa investigação, trazemos no quadro a seguir, uma listagem dessas pesquisas.

Quadro 1: Os trabalhos analisados

\begin{tabular}{|c|}
\hline \\
\hline $\begin{array}{l}\text { ABREU, Glaucos Ottone Cardoso de. A prática de Modelagem Matemática como um cenário de } \\
\text { investigação na formação continuada de professores de matemática. 2011. } 102 \text { p. Dissertação (Mestrado } \\
\text { Profissionalizante em Educação Matemática), Universidade Federal de Ouro Preto, Ouro Preto, } 2011 \text {. }\end{array}$ \\
\hline $\begin{array}{l}\text { bre as atividades de Modelagem Matemática a partir da } \\
113 \text { p. Dissertação (Mestrado em Educação em Ciências e } \\
\text { m, } 2011 \text {. }\end{array}$ \\
\hline $\begin{array}{l}\text { DIAS, Michele Regiane. Uma experiência com Modelagem Matemática na formação continuada de } \\
\text { professores. 2005. } 100 \text { p. Dissertação (Mestrado em Ensino de Ciências e Educação Matemática), Universidade } \\
\text { Estadual de Londrina, Londrina, } 2005 \text {. }\end{array}$ \\
\hline $\begin{array}{l}\text { FERREIRA, Carlos Roberto. Modelagem Matemática na Educação Matemática: contribuições e desafios à } \\
\text { formação continuada de professores na modalidade Educação a Distancia online. 2010. } 100 \text { p. Dissertação } \\
\text { (Mestrado em Educação), Universidade Estadual de Ponta Grossa, Ponta Grossa, 2010. }\end{array}$ \\
\hline $\begin{array}{l}\text { SOUZA, Ricardo Antonio de. A Modelagem Matemática como proposta de ensino e aprendizagem do } \\
\text { conceito de função. 2011. } 107 \text { p. Dissertação (Mestrado Profissionalizante em Educação Matemática), } \\
\text { Pontifícia Universidade Católica de São Paulo, São Paulo, 2011. }\end{array}$ \\
\hline $\begin{array}{l}\text { ROSA, Selma dos Santos. Possibilidades dos processos e método no ensino a distância: um estudo de caso de } \\
\text { um curso de Modelagem Matemática. 2009. } 150 \text { p. Dissertação (Mestrado em Educação), Universidade Regional } \\
\text { de Blumenau, Blumenau, 2009. }\end{array}$ \\
\hline $\begin{array}{l}\text { MACHADO, Simone Raquel Cassarin. Percepções da Modelagem Matemática nos anos iniciais. 2010.150 p. } \\
\text { Dissertação (Mestrado em Educação Científica e Tecnológica), Universidade Federal de Santa Catarina, } \\
\text { Florianópolis, } 2010 \text {. }\end{array}$ \\
\hline $\begin{array}{l}\text { MALHEIROS, Ana Paula dos Santos. Educação Matemática online: a elaboração de projetos de Modelagem } \\
\text { 2008. } 187 \text { p. Tese (Doutorado em Educação Matemática), Universidade Estadual Paulista Júlio de Mesquita } \\
\text { Filho, Rio Claro, } 2008 \text {. }\end{array}$ \\
\hline
\end{tabular}

Fonte: Os autores

De posse das 8 investigações, passamos ao processo de análise. Nesse processo, utilizamos o software de apoio à análise qualitativa Atlas T.i., que ajuda a organizar, registrar e acompanhar o movimento analítico efetuado pelo pesquisador. Destacamos que as principais funcionalidades do software, abordadas sob diferentes perspectivas, podem ser aprofundadas, por exemplo, em Klüber e Burak (2012) e Walter e Bach (2009). Também nos apropriamos do trabalho de Klüber (2014) que apresenta esse software no contexto da abordagem fenomenológica.

Desse modo, com o auxílio do software e à luz da interrogação de pesquisa: O que se mostra das atividades de formação continuada de professores nas pesquisas de dissertações e teses de Modelagem na Educação Matemática? buscamos os invariantes que emergiram das 
atividades de formação continuada, relatadas nas dissertações e na tese. A leitura destas se deu com o objetivo de destacar e estabelecer as unidades de significado que não se encontram prontas no texto, mas são decorrentes do movimento intencional da pesquisa à luz da interrogação.

Uma vez estabelecidas estas unidades, retomamos a sua leitura para o entrelaçamento dos significados. Ou seja, buscou-se sair de um momento individualizado para chegar às convergências ou à constituição das grandes categorias ou categorias abertas. Estas expressam a rede de significados da estrutura do fenômeno, mostrando como cada unidade se articula. Estes procedimentos fenomenológicos indicam o ato de redução ou uma epoché, em que, abstrativamente, o pesquisador dintingue a essência do fenômeno, superando a visão primeira (BICUDO, 2006, BICUDO; KLÜBER, 2013).

Ressaltamos que a pesquisa qualitativa sob o enfoque fenomenológico

$$
\begin{aligned}
& \text { trabalha sempre com o qualitativo, com o que faz sentido para o sujeito, com o } \\
& \text { fenômeno posto em suspensão, como percebido e manifesto pela linguagem; e } \\
& \text { trabalha também com o que se apresenta como significativo ou relevante no } \\
& \text { contexto no qual a percepção e a manifestação ocorrem (BICUDO, 2000, p.74). }
\end{aligned}
$$

Além de trabalhar com o que "faz sentido", com o "qualitativo", uma atitude fenomenológica "exige o rompimento com a atitude natural e sua tese, as ideias pré-concebidas, as aparências, o acessório, o acidental; o cultivo do rigor e da racionalidade no pensar e no agir, enfim, uma atitude completamente nova diante do real" (COELHO, 1999, p. 88).

As interpretações das categorias foram efetuadas hermeneuticamente. Essa afirmação traz consigo "a ideia de tornar explícito o implícito, de descobrir a mensagem, de torná-la compreensível, envolvendo a linguagem nesse processo" (HERMANN, 2002, p. 24). Destacamos que envolver a linguagem na interpretação hermenêutica significa renunciar à verdade absoluta e "reconhecer que pertencemos às coisas ditas, aos discursos, abrindo uma infinidade de interpretações possíveis" (idem).

Bicudo (1993) ao tratar da hermenêutica acrescenta que "ela permite, ao mesmo tempo, que o intérprete compreenda o mundo (realidade onde vive, da qual partilha e a qual fabrica) e se compreenda (enquanto pessoa individual e como ser humano)"(p. 65). Essa explicitação vai ao encontro daquela efetuada por Hermann (2002) na qual compreende que essa interpretação 
não se restringe ao texto escrito, mas o ultrapassa, e mais do que isso, se refere "a uma manifestação vital que afeta as relações dos homens entre si e com o mundo" (p. 25).

A partir da explicitação da perspectiva assumida nesse trabalho, nossa exposição, a seguir, se centra na análise e interpretação das categorias.

\section{Análise e Interpretação}

No âmbito da metodologia assumida e das descrições efetuadas, foram estabelecidas 7 categorias que emergiram das unidades de signicado destacadas das dissertações e da tese analisadas. Estas são apresentadas no quadro a seguir e, são expostas de tal modo, que na primeira coluna organizamos as suas representações, isto é, à primeira categoria atribuímos o símbolo C1 e, assim sucessivamente. Já na segunda coluna apresentamos os nomes dessas categorias, que dizem das unidades de significado.

Quadro 2: As categorias

\begin{tabular}{|c|l|}
\hline CATEGORIA & \multicolumn{1}{|c|}{ NOME } \\
\hline C1 & Sobre os professores participantes \\
\hline C2 & Sobre os objetivos das atividades \\
\hline C3 & Sobre a duração, a modalidade, o contexto e a natureza das atividades \\
\hline C4 & Sobre os modos de abordar as teorias nas atividades \\
\hline C5 & Sobre as concepções de Modelagem Matemática \\
\hline C6 & Sobre o desenvolvimento das atividades de Modelagem na prática docente \\
\hline C7 & Sobre as ferramentas auxiliares utilizadas nos cursos ofertados na modalidade EaD \\
\hline
\end{tabular}

Fonte: Os autores

A categoria, C1 - Sobre os professores participantes, no âmbito da formação continuada, revela que eles são formados em Matemática ou áreas afins e que atuam nas Séries Iniciais, na Educação Básica e no Ensino Superior. No que diz respeito ao número de professores participantes, destacamos que as atividades contemplam arranjos variados, de 5 a 35 professores.

Os professores, em geral, são convidados a participar destas atividades e, portanto, fica ao seu critério engajar-se. Por um lado, as atividades poderiam receber mais participantes, contudo 
fica evidente a baixa procura. De outro, nas atividades com maior número de inscritos há um considerável número de desistências.

A baixa procura e a desistência podem estar relacionadas a diversos fatores, como a cultura escolar do professor, a dimensão burocrática da escola, aos modelos das atividades ofertadas, aos tipos de atividades, (curso, programa de formação, oficinas e disciplina em programa de pós-graduação), às modalidades em que elas foram veiculadas, ao nível da pesquisa em que a atividade estava inserida. Como os professores participantes das atividades analisadas são, em sua maioria, apenas da Educação Básica, revela-se uma ausência de procura por formação no âmbito do Ensino Superior e, também, um endereçamento da formação aos professores da Educação Básica.

Nesse contexto, destaca-se que há no âmbito da pesquisa em Educação Matemática, uma crença de que os problemas da aprendizagem estão relacionados ao nível básico da formação escolar. Nesse sentido, as propostas, convergem para um ideal que é implicitamente veiculado nas discussões sobre a qualidade do ensino e da aprendizagem da Matemática. A Modelagem Matemática, por sua vez, é tomada em seu potencial de solucionar alguns dos problemas do ensino e aprendizagem da Matemática, o que pode ser visto em documentos oficiais e outros relatórios de pesquisa nacional e internacional e na literatura sobre o assunto.

Do ponto de vista histórico, da trajetória de formação de professores no Brasil, sabe-se que grande parte não teve acesso, em sua formação inicial, às atuais tendências da Educação Matemática. Assim, as propostas visam, em sentido amplo, suprir ou sanar uma ausência da formação de professores na Educação Básica.

O número de participantes das atividades revela o nível exploratório das pesquisas. Em outras palavras, são pesquisas de pequeno porte e de pouco alcance teórico e prático. A maioria delas conta com poucos participantes, o que expressa a pontualidade da investigação situada apenas no contexto da produção da dissertação ou da tese, sem se vincular a projetos de pesquisa mais amplos, sobre a formação de professores. Essa caraterística mostra a incipiência para uma contribuição efetiva - de fronteira ao campo - tendo em vista que a formação de professores requer pesquisas com intervalos de tempo mais amplos e a consideração de aspectos culturais que estão presentes na ação docente.

A partir dos dados coletados, revela-se que algumas das atividades desenvolvidas em nível de formação continuada explicitam os seus objetivos, apresentados na categoria: C2 - Sobre os 
objetivos das atividades. Elas buscavam proporcionar que o professor: 1) aprendesse sobre e por meio da Modelagem, além de encorajá-lo a usar a Modelagem na sala de aula; 2) modelasse matematicamente, aguçasse a criatividade e adaptasse o processo utilizado para modelar nas práticas pedagógicas; 3) desenvolvesse projetos de Modelagem Matemática para o ensino de funções; 4) efetuasse discussões e reflexões sobre aspectos concernentes à prática do professor e ao seu crescimento profissional. Enfim, as atividades tinham em seu âmago o objetivo de aproximar e envolver os professores em atividades de Modelagem, com características pontuais ou mais abrangentes.

Esses objetivos podem evidenciar a concepção que se tem de que os professores aprenderão a fazer Modelagem a partir do momento em que estiverem na condição de aluno. Essa concepção pode, em certo sentido, contribuir para que os professores se aproximem da Modelagem em termos mais práticos e não apenas teóricos. E se a atividade de formação for desenvolvida razoavelmente e assumida com preocupações mais amplas relacionadas à formação dos professores, ela pode favorecer um momento no qual os professores discutam, por exemplo, alternativas para a implementação dessa tendência no contexto educacional.

No entanto, esse momento de reflexão e discussão acerca da prática docente tende a ser superficial ou nem chega a acontecer, devido às próprias características das atividades de formação continuada, uma vez que, em muitos casos, a duração e o formato na qual foram assumidas não contribuem para esse momento. Nessa perspectiva, o argumento de que se aprende Modelagem Matemática fazendo-a, o qual parece sustentar as propostas de atividades, não se mantém. Essa posição pode ser contraposta ao reconhecermos que a Modelagem Matemática não é concebida de modo homogêneo e permanece, neste argumento, apenas num sentido geral da aprendizagem, sem adentrar em especificidades da Modelagem, da formação de professores e de aquisições de competências profissionais. Além disso, argumentamos que o professor participante dessas atividades não deve ser colocado, simplesmente, na condição de aluno, mas na condição de aprendente. Este é entendido como alguém que aprende sem perder as suas características pessoais, profissionais e intelectuais de professor.

A categoria revela, ainda, a própria concepção de formação de professores daqueles que propuseram as atividades de formação continuada. E a partir das unidades de significado destacadas das dissertações e tese analisadas, revela-se que muitas dessas atividades estão 
centradas em aspectos pontuais da Modelagem Matemática, buscando, desse modo, preparar o professor para uma "especificidade técnica", que nesse caso é desenvolver uma atividade de Modelagem.

De acordo Imbernón, (2010) a formação de professores na Espanha "persiste num processo composto de lições-modelo, de noções oferecidas em cursos, de uma ortodoxia do ver e do realizar a formação, de cursos padronizados [...]" (idem, p.8). Em certo sentido, a descrição dada pelo autor também pode ser vista nessa categoria, revelando, como já dito, a concepção subjacente aos processos formativos.

Nesse contexto, ao criticar os processos de formação com essas características, o autor chama a atenção para o fato de que a formação não deve ficar restrita a noções ou disciplinas, ela deve se caracterizar por uma formação em um "maior conhecimento subjetivo: autoconceito, conflito, conhecimento de si, comunicação, dinâmica de grupos, processos de tomadas de decisão coletivas, etc (idem, p. 43)". Apesar de essa não ser uma perspectiva única, ela se mostra razoável, para esclarecer as concepções que emergiram do fenômeno investigado.

Na categoria, C3 - Sobre a duração, a modalidade, o contexto e a natureza das atividades, descrevemos e interpretamos alguns aspectos concernentes às atividades de formação continuada, no que se refere a duração (incluindo o número de encontros e a carga horária destinada as atividades como um todo e as suas partes), modalidade, contexto e a natureza delas.

Quanto à duração elas se mostram com características pontuais, com apenas 2 encontros de duas horas cada; 3 encontros, sendo que 2 tiveram duração de 4 horas e 1 com duração de apenas 1 hora; 4 oficinas de 4 horas/aula cada. Outras atividades foram mais extensas contemplando 14 encontros semanais de 2 horas e meia cada; 16 encontros com um total de 40 horas de duração distribuídas num período de 80 dias; 39 horas sem especificar como essas horas foram distribuídas e, por fim, uma disciplina no âmbito de um curso de especialização de 360 horas sem explicitar a carga horária da disciplina na qual a atividade foi desenvolvida.

No que se refere à modalidade, dentre as 8 atividades de formação continuada, 5 foram desenvolvidas na modalidade presencial e 3 na modalidade EaD. 
Quanto a natureza e o contexto, identificamos que elas foram denominadas de oficinas, cursos de extensão, programa de formação e disciplinas específicas ofertadas na própria escola e em nível de pós-graduação lato e stricto sensu.

Em primeiro lugar, a interpretação aponta para as concepções de formação de professores, de Modelagem Matemática, de ensino e aprendizagem dos pesquisadores que as propuseram. Em segundo, pode ir ao encontro da urgência que os professores têm em utilizar diferentes metodologias em sala de aula. Isto é, há uma "pressa" de sua parte em se ambientar com as tendências em Educação Matemática. De certo modo, essa situação desdobra-se em atividades de formação continuada extremamente rápidas. Assim, as propostas se configuram em ofertas de "receitas" para serem utilizadas, em sala de aula, pelos professores.

Entretanto, para que tenhamos um processo de formação que contribua efetivamente para a melhoria da prática docente e para o contexto geral da sala de aula, esse imediatismo requerido pelos professores e, muitas vezes ofertado nas atividades de formação continuada, pode não contribuir para uma mudança significativa. Nesse sentido, Klüber (2012, p. 66) afirma que

[...] a superação de obstáculos ou mesmo o rompimento com práticas consideradas inadequadas no âmbito de um coletivo de pensamento não são metas simples de serem alcançadas pelos professores, que, habitualmente, buscam soluções mais rápidas para a sua atuação em sala de aula.

Por se tratar de atividades com uma carga horária reduzida, a grande maioria restringe-se ao envolvimento dos professores em atividades de Modelagem, na condição de aluno, sem possibilitar um momento de discussão sobre a prática docente, ou outras discussões referentes à prática profissional do professor. Há, portanto, traços de uma concepção pragmatista, de cunho técnico, muito mais informativa do que formativa.

Assim, ao tratar da formação de professores, Nóvoa (1995) citado por Gonçalves (2006, p. 52) explicita que ela "não se constrói por acumulação de (cursos, de conhecimento ou de técnicas), mas, sim, através de um trabalho de reflexividade crítica sobre a prática e de (re)construção permanente de uma identidade profissional". Esse contexto discutido pelo autor favorece a compreensão de que as atividades de Modelagem se vinculam à essa tradição formativa. 
Ainda no sentido de indicar alguns aspectos que poderiam ser contemplados na formação de professores, acrescenta-se à afirmação de Nóvoa, o apresentado por Imbernón (2010, p. 45) quando esclarece que "a formação continuada deveria fomentar o desenvolvimento pessoal, profissional e institucional dos professores, potencializando um trabalho colaborativo para transformar a prática".

Para além da perspectiva apontada pelos autores, destacamos que as concepções que orientam os processos formativos em Modelagem não se diferenciam de processos que vêm sendo debatidos e mesmo refutados no âmbito da formação de professores, em específico no âmbito da Modelagem. Como já expusemos o tema de pesquisa em formação de professores no âmbito da Modelagem é recente, no entanto, as concepções veiculadas se alinham a concepções antigas.

$\mathrm{Na}$ categoria, C4 - Sobre os modos de abordar a teoria nas atividades, desvela-se que a maioria delas inicia-se com a explicitação de aspectos concernentes à teoria. De um modo geral, os primeiros encontros são destinados à apresentação das distintas concepções de Modelagem Matemática ou algum outro referencial que "sustente" as propostas das atividades. Apenas uma delas fez o caminho contrário: envolveu os professores em atividades de Modelagem para depois abordar os aspectos teóricos.

O fato de a maioria das atividades de formação iniciar com a teoria pode revelar a presença de elementos do paradigma dominante. Neste, sustenta-se que, primeiramente, é preciso conhecer a teoria para só em seguida dar início a parte prática. Pode revelar, também, a formação do pesquisador/proponente da atividade de Modelagem, haja vista que, quando não há uma reflexão acerca dos processos formativos, tende-se a reproduzir as ações e concepções as quais foram expostos.

Em complemento ao interpretado, recorremos à Imbernón (2010), que apresenta em seus estudos o quanto somos influenciados pelos processos de formação aos quais nos submetemos. Isso pode refletir nas atividades de formação propostas por professores que não asssumem o hábito e não estão dispostos a discutir a formação que tiveram: “[...] esses docentes foram formados no autoritarismo, com fundo positivista e como uma visão técnica de um ofício no qual havia soluções teóricas para tudo e para todos [...]” (p. 19).

Há uma variedade no que diz respeito às concepções de Modelagem Matemática assumidas nas atividades de formação continuada, isso se expressou na categoria: C5 - Sobre as 
concepções de Modelagem Matemática. As principais são: a Modelagem como ambiente de aprendizagem (Barbosa, 2001); a Modelagem como metodologia de ensino de Matemática (Burak, 2004), a Modelagem como alternativa pedagógica (Almeida, 2003) e ainda a apresentação das diversas perspectivas. De um modo geral, estão relacionadas aos orientadores, que são pesquisadores significativos da área.

Assumir determinada concepção para o desenvolvimento das atividades de formação influencia diretamente no modo como o professor será conduzido ao "fazer modelagem" e, certamente, influenciará a prática desse professor em sala de aula caso ele decida utilizar essa tendência com os seus alunos.

Em certo sentido, essa categoria revela o confronto teórico e prático que permenece no interior da comunidade. As dissertações e a tese, por sua vez, contemplam aspectos mais amplos para além da concepção assumida. No entanto convergem para práticas específicas que são justificadas pelas escolhas feitas. Em outras palavras, desvela-se o diálogo e o distanciamento no interior da comunidade de Modelagem Matemática quando o foco é a formação de professores. Ainda, descortina-se a preocupação em apresentar as distintas compreensões, mais ou menos aprofundadas conforme a atividade desenvolvida. A teoria veiculada sobre as concepções se mostra como uma possibilidade de abrir-se ao novo e reconfigurá-lo em-prática.

Esse cuidado de apresentar diferentes concepções cumpre o papel de evidenciar a não homogeneidade das teorias e práticas de Modelagem. Por um lado pode ser visto como um posionamento crítico sobre o debate interno da comunidade. De outro lado, retomando a categoria da duração das atividades, somos autorizados a afirmar que o impacto nas práticas dos professores fica reduzido, por não assumir uma perspectiva, ou ao assumi-la, ela é abordada brevemente e sem o devido aprofundamento. Em resumo, essas propostas apenas tangenciam esses aspectos.

Na categoria, C6 - Sobre o desenvolvimento de atividades de Modelagem na prática docente, quatro atividades de formação continuada propuseram que os professores a implementassem no contexto da sala de aula. Três dessas implementações aconteceram concomitantemente aos encontros propostos na atividade. Desse modo, os professores poderiam socializar as experiências com os pares e sanar suas dúvidas. Uma implementação 
ocorreu após o término dos encontros de formação com o acompanhamento das professoras por parte do pesquisador.

Destacamos aqui, um ponto relevante dessas atividades, uma vez que proporcionaram momentos de discussão e reflexão entre os pares, constatação que vai ao encontro de um dos aspectos defendidos como importantes nesse processo de formação continuada.

[...] a formação continuada proporciona aos professores uma (re)elaboração de seus saberes iniciais em confronto com suas experiências práticas, num processo coletivo de troca de experiências. (DIAS; ALMEIDA, 2004, p. 3).

As unidades de significado desta categoria evidenciam a preocupação de algumas das atividades de formação continuada em proporcionar ao professor um contato com a Modelagem e a sua prática em sala de aula. Isto é, transcender a mera leitura de textos e superar o desenvolvimento de atividades na condição de aluno. Essa preocupação ou até mesmo essa mudança no perfil de determinadas atividades de formação pode ter vínculo com as próprias expectivas dos professores envolvidos no processo. Isto porque há um descontentamento quando essas atividades se restringem apenas à aspectos teóricos sem uma aproximação com a sua prática de sala de aula.

O fato de a maioria das implementações de Modelagem nas práticas docentes terem sido executadas no decorrer das atividades de formação expõe a necessidade em se realizar tais atividades por um período de tempo maior. Para que, além de sanar as suas dúvidas, os professores possam, caso isso seja propiciado, socializar a sua experiência em sala de aula e consolidar em-prática a nova perspectiva.

Ressaltamos ainda que, ao valorizar o espaço da prática do professor, em seu trabalho cotidiano, ele passa a ser visto não apenas como um lugar de aplicação de saberes produzidos por outros, mas também como um espaço de produção, de transformação e de mobilização de saberes que lhe são próprios (TARDIF, 2012).

$\mathrm{Na}$ categoria, C7 - Sobre as ferramentas auxiliares utilizadas nos cursos ofertados na modalidade EaD, a partir das unidades estabelecidas, destacaram-se as que seguem: ferramenta wiki que possibilita uma forma de interação colaborativa; videoconferência para a transmissão de aulas virtuais; chat para realização de encontros constantes e elaboração de projetos de Modelagem e ainda a plataforma Moodle que contempla várias ferramentas interativas, como por exemplo chat e fórum. Essa categoria tem um significado especial, pois 
ela se expressa, especificamente, no âmbito da Modalidade de Educação a Distância. Dito de outro modo, as unidades que a compõem só têm sentido no contexto desta modalidade, pois de outro modo, não encontrariam ressonância e pertinência de serem destacadas. A partir dela revela-se, entre outras coisas, um movimento de apologia à Modelagem Matemática em outra instância. A defesa pela adoção da Modelagem e as limitações em sua divulgação e socialização em modalidades presenciais, como a nossa análise e interpretação confirmou, abriu um campo de investigação na modalidade a distância. A nossa interpretação indica que ocorreu uma transposição dos fundamentos assumidos de Modelagem para as plataformas de EaD.

Nesse contexto, desvelou-se uma apologia ao uso das ferramentas desta modalidade, como potencialmente significativas para a superação de problemas próprios da modalidade presencial, como, por exemplo, temporais e espaciais. Além disso, as ferramentas poderiam favorecer interatividade e algum grau de vinculação entre professor participante e pesquisador.

Esse provável favorecimento é identificado ao olharmos para as características dessas ferramentas. O Wiki, por exemplo, é uma ferramenta importante dentro da plataforma do Moodle e, permite a edição de textos com gerenciamento de versões. Além disso, ele pode ser utilizado para desenvolver trabalho de maneira cooperativa, no qual vários integrantes de um grupo podem participar do processo de escrita.

Outras ferramentas, como o chat e o fórum, utilizadas nesses trabalhos, também apresentam aspectos que contribuem para que, em certo sentido, a "distância" seja diminuída e os professores possam trocar experiências e o contato entre os pesquisadores e os professores se tornem frequentes mesmo com a problemática do distanciamento geográfico.

Destacamos, a partir dessa compreensão, que apesar de existir a preocupação em levar a formação de professores em Modelagem para um contingente maior de professores, por meio da modalidade $\mathrm{EaD}$, é razoável afirmar, desde essas interpretações, que há a necessidade do estabelecimento de problemas de pesquisa mais amplos que envolvam a formação de professores em Modelagem nesse tipo de modalidade educacional. 


\section{À Guisa de Conclusão}

As interpretações efetuadas ao longo dessa investigação nos permitem afirmar que há uma crença implítica, por parte daqueles que se propõem a ofertar atividades de formação continuada, que "fazer" Modelagem Matemática favorece o trabalho com essa tendência em Educação Matemática enquanto professor. Essa crença pode encontrar uma justificativa no fato de a Modelagem ser derivada da Matemática Aplicada. O que, em certo sentido, contribui para a ideia de um pragmatismo no enfrentamento das situações de formação de professores.

Ainda relacionado à afirmação efetuada destacamos que ela, de um modo geral, se sustenta. Uma vez que, a partir desse "fazer" Modelagem os professores passam a ter um contato mais próximo com essa tendência. No entanto, o modo como essa aproximação tem sido realizada não tem contribuído para que haja uma efetiva implementação da Modelagem Matemática no contexto da sala de aula. Em outras palavras, pode-se defender que, muito mais do que apresentar aos professores essa tendência, as atividades de formação continuada precisam acompanhar os professores em sua prática docente e desenvolver outras maneiras de estabelecer os processos formativos.

Desse modo, pelas dissertações e tese analisadas, revela-se que a reflexão sobre os processos de formação de professores está sendo relegada a um segundo plano em detrimento da própria Modelagem. Nesse sentido, acrescentamos que saber sobre Modelagem é um dos aspectos necessários nas atividades de formação continuada, mas não é o suficiente. Assim, cabe questionar que outros aspectos se fazem complementares.

Essas atividades revelaram, ainda, a concepção de transferência ou transmissão de conhecimentos em que os próprios pesquisadores foram formados tendo em vista as concepções acerca da formação do professor que emergiram. Isto é, concepções que na maioria das vezes estavam voltadas à aspectos pontuais do conteúdo matemático e da tendência em Educação Matemática abordada, sem uma reflexão mais ampla sobre o contexto da sala de aula e sobre aspectos da própria formação do professor, que vão além de discussões voltadas à disciplina em questão, ou ao domínio do conteúdo. Abrange características da postura do professor, do incentivo e formação relacionada à mudança na sua prática. De discussões que não se prendam a uma ou outra teoria e, que tenha como foco contribuições efetivas para a sala de aula. 
Nesse contexto, as interpretações e discussões efetuadas ao longo da investigação, revelam a urgência de a comunidade de Modelagem realizar estudos voltados à formação de professores, de modo particular, à formação continuada. Estudos que transcendam o nível exploratório de pesquisa e, que tragam reflexões e contribuições efetivas para a formação de professores em Modelagem Matemática.

\section{Referências}

ALMEIDA, Lourdes Maria Werle de. Algumas reflexões sobre a pesquisa em Modelagem Matemática. In: Seminário Internacional de Pesquisa em Educação Matemática, 3, 2006, Águas de Lindóia - SP. Anais... . Curitiba: SBEM, 2006.

. Modelagem Matemática em sala de aula: em direção à educação matemática crítica.

In: Conferênia Nacional sobre Modelagem na Educação, 3., Piracicaba - SP. Anais... Piracicaba, 2003.

ARAÚJO, Jussara de Loiola. Pesquisas sobre Modelagem em eventos científicos recentes de educação matemática no Brasil. In: Seminário Internacional de Pesquisa em Educação Matemática - 4, 2009, Taguatinga, DF. Anais ... . Taguatinga: UCB, 2009. p. 1-14.

BARBOSA, Jonei Cerqueira. Modelagem na Educação Matemática: Contribuições para o detabe teórico. In: Reunião Anual da ANPED, 24, 2001. Caxambu. Anais... Caxambu: AMPED, 2001.

. Sobre a pesquisa em modelagem matemática no Brasil. In: Conferência Nacional sobre Modelagem na Educação Matemática, 5, novembro de 2007. Ouro Preto, Anais... Universidade Federal de Ouro Preto/Universidade Federal de Minas Gerais, 2007. p. 82-103.

; ARAÚJO, Jussara de Loiola; CALDEIRA, Ademir Donizeti; GT 10 - Modelagem Matemática: relatório das sessões do GT10 no IV SIPEM. SBEM: 2009. Disponível em: http://www.sbem.com.br/gt10/pdf/relatorio_ivsipem.pdf. Acesso em 05 de fevereiro 2013.

BICUDO. Maria Aparecida Viggiani. A hermenêutica e o trabalho do professor de matemática. Cadernos da Sociedade de Estudos e Pesquisa Qualitativos. v. 3, n. 3, 1993, p. 61-94.

. Fenomenologia: Confrontos e avanços: São Paulo: Cortez, 2000.

. Pesquisa Qualitativa e Pesquisa Qualitativa segundo a abordagem fenomenológica. In: BORBA; Marcelo de Carvalho; et al. Pesquisa Qualitativa em Educação Matemática. Belo Horizonte: Autêntica, 2006.

Pesquisa qualitativa: segundo a visão fenomenológica. São Paulo: Cortez, 2011. 
; KLÜBER, Tiago Emanuel. Pesquisa em modelagem matemática no Brasil: a caminho de uma metacompreensão. Cadernos de Pesquisa, São Paulo, v.41, n.144, p.902-925, set./dez. 2011.

; KLUBER, Tiago Emanuel. A questão da pesquisa sob a perspectiva da atitude fenomenológica de investigação. Conjectura: Filos. Educ., Caxias do Sul, v.18, n.3, p.2440,set/dez.2013

; PAULO, Rosa. Monteiro. Um Exercício Filosófico sobre a Pesquisa em Educação Matemática no Brasil. Bolema, Rio Claro, SP, v. 25, n. 41, p. 251-298, dez. 2011.

BURAK, Dionísio. Modelagem Matemática e a Sala de Aula. In: I Encontro Paranaense de Modelagem na Educação Matemática. I EPMEM, 2004, Londrina:UEL, Anais..., 2004.

COELHO, Ildeu Moreira. Fenomenologia e Educação. In: BICUDO, Maria Aparecida Viggiani; CAPPELLETTI, Isabel Franchi (Org). Fenomenologia: Uma visão abrangente da Educação. São Paulo: Olho d'água, 1999.

DIAS, Michele Regiane; ALMEIDA, Lourdes Maria Werle de. Formação de professores e Modelagem Matemática. In: Encontro Nacional de Educação, 8., 2004, Recife. Anais... Recife: SBEM, 2004.

GONÇALVEZ, Tadeu Oliver. A constituição do formador de professores de matemática: a prática formadora. Belém: CEJUP, 2006.

HERMANN, Nadja. Hermenêutica e Educação. Rio de Janeiro: DP\&A, 2002.

IMBERNÓN, Francisco. Formação Continuada de Professores. Porto Alegre: Artmed, 2010 .

KLÜBER, Tiago Emanuel; BURAK, Dionísio. Sobre a Pesquisa Qualitativa na Modelagem Matemática em Educação Matemática. Bolema. Boletim de Educação Matemática (UNESP. Rio Claro. Impresso), 2012.

Uma metacompreensão da Modelagem Matemática na Educação Matemática. 2012. 396 f. Tese (Doutorado em Educação Científica e Tecnológica) - Centro de Ciências Físicas e Matemática, Universidade Federal de Santa Catarina, Florianópolis, 2012.

- (Des) Encontros entre a Modelagem Matemática na Educação Matemática e a formação de professores de Matemática. Alexandria. Santa Catarina, v. 5, n. 1, p. 63-84, 2012.

Atlas. ti como instrumento de análise em pesquisa qualitativa de abordagem fenomenológica. ETD - Educação Temática Digital. Campinas, v. 16, n. 1, p. 5-23, 2014.

NISS, Mogens. Issues and problems of research on the teaching and learning of applications and modelling. In J. F. Matos, W. Blum, S. K. Houston \& S. P. Carreira (Eds.), Modelling and mathematics education - ICTMA 9: Applications in science and technology (pp. 7288). Chichester: Horwood Publishing, 2001. 
PALMER, Richard. E. Hermenêutica. trad. Maria Luísa Ribeiro Ferreira. Lisboa: Edições 70,1996. (Coleção o Saber da Filosofia).

PARANÁ. Secretaria de Estado de Educação. Programa de Desenvolvimento Educacional PDE. Documento síntese. Curitiba: SEED, 2013.

TAMBARUSSI, Carla Melli; KLÜBER, Tiago Emanuel. Focos da pesquisa stricto sensu em Modelagem Matemática na Educação Matemática brasileira: considerações e reflexões. Educação Matemática Pesquisa. São Paulo, v. 16, n. 1, p. 209-225, 2014.

TARDIF, Maurice. Saberes Docentes e formação profissional. Petrópolis, RJ: Vozes, 2012.

WALTER, Silvana Anita; BACH, Tatiana Marceda. Adeus papel, marca-textos, tesoura e cola: Inovando o processo de análise de conteúdo por meio do Atlas. In: Seminários de Empreendendorismo e Educação, 12, 2009. São Paulo. Anais... São Paulo: USP, 2009. 